\title{
Advancement Flap for the Treatment of a Complex Anal Fistula
}

\author{
Do Sun Kim \\ Department of Surgery, Daehang Hospital, Seoul, Korea
}

\section{See Article on Page 192-196}

The aim of surgical treatment for an anal fistula is to cure the disease, as well as to preserve continence. Treatment of a complex anal fistula has been a surgical challenge. Therefore, various sphincter-preserving procedures have been introduced for its treatment due to concerns of incontinence. One of the oldest and most widely performed procedures is the advancement flap.

The procedure of an advancement flap may be summarized as elevating a flap, coring out of a infected gland, as well as an epithelized internal opening, suturing of the internal sphincter defect, closing the wound with a flap, and providing effective drainage. Although a mucosal flap has been used traditionally, recently a dermal island or cutaneous flap has been used for the same purpose. Compared with a mucosal advancement flap, these procedures may have advantages in terms of technical aspects because they may provide easier access for the operation. They also reduce mucosal ectropion and discharge.

However, advancement flap procedures have limitations. They are technically-demanding procedures with a wide range of success rates and are not free from a risk of minor incontinence [1]. Some investigators have tried different approaches such as direct closure of a fistula tract or intersphincteric access to a fistula tract. Techniques for direct closure of a fistula tract, which include the use of fibrin glue and a fistula plug, seem to be ideal because they are very simple procedures and do not cause any harm to the sphincter mechanisms. However, these techniques have a wide range of success rates and do not seem to be durable and reliable

Correspondence to: Do Sun Kim, M.D.

Department of Surgery, Daehang Hospital, 2151 Nambusunhwan-ro, Seocho-gu, Seoul 137-820, Korea

Tel: +82-2-6388-8114, Fax: +82-2-6388-8673

E-mail: dskim1@daehang.com

(C) 2014 The Korean Society of Coloproctology

This is an open-access article distributed under the terms of the Creative Commons Attribution NonCommercial License (http://creativecommons.org/licenses/by-nc/3.0) which permits unrestricted noncommercial use, distribution, and reproduction in any medium, provided the original work is properly cited. procedures. Ligation of the intersphincteric fistula tract (LIFT) is an intersphincteric approach that has gained wide popularity recently. Success rates of LIFT reported in the literature are around 70 percent, which is comparable to that of the flap procedure. However, most studies on LIFT involved low or high transsphincteric fistulae [2]. Therefore, whether this procedure can result in comparable results when it is performed for more complex types of fistulae is a concern.

Combining fibrin glue with a mucosal advancement flap was tried in an effort to improve the result from an advancement flap [3]. However, contrary to expectations, the success rate of the combined procedure was less than that of the mucosal flap alone. Fibrin glue injection may have prevented effective drainage, and accumulated discharge may have burst into the internal opening. Therefore, any procedure that results in stasis of discharge or prevents effective drainage may produce a poor result.

Seton placement prior to an advancement flap may be helpful in terms of sepsis control. However, whether seton placement is mandatory even in cases of a fistula without active inflammation is controversial. Although seton placement may be helpful in improving the success rate of a therapeutic procedure, no solid data showing that the seton is an indispensible procedure for an advancement flap are available [4]. Also, concerns about delaying a definitive treatment may exist.

Some investigators have reported a good result for an advancement flap after seton placement. They closed the internal and the external openings with a mucosal flap and a cutaneous flap, respectively [5]. However, the number of study cases was too small to reach a significant conclusion, and as mentioned earlier, of the possibility of ineffective drainage is a concern when the external orifice is closed at the same time as the internal opening.

In short, despite the limitations of flap procedures, there is still no reliable, alternative measure for treating a complex anal fistula. If the result after a flap procedure is to be satisfactory, every step of the procedure should be performed accurately, and no other procedure that may have an adverse effect on the healing process should be incorporated. 


\section{REFERENCES}

1. Uribe N, Millan M, Minguez M, Ballester C, Asencio F, Sanchiz V, et al. Clinical and manometric results of endorectal advancement flaps for complex anal fistula. Int J Colorectal Dis 2007;22:259-64.

2. Yassin NA, Hammond TM, Lunniss PJ, Phillips RK. Ligation of the intersphincteric fistula tract in the management of anal fistula. A systematic review. Colorectal Dis 2013;15:527-35.

3. van Koperen PJ, Wind J, Bemelman WA, Slors JF. Fibrin glue and transanal rectal advancement flap for high transsphincteric peri- anal fistulas; is there any advantage? Int J Colorectal Dis 2008;23: 697-701.

4. Mitalas LE, van Wijk JJ, Gosselink MP, Doornebosch P, Zimmerman DD, Schouten WR. Seton drainage prior to transanal advancement flap repair: useful or not? Int J Colorectal Dis 2010;25: 1499-502.

5. Ertem M, Gok H, Ozveri E, Ozben V. Application of advancement flap after loose seton placement: a modified two-stage surgical repair of transsphincteric anal fistula. Ann Coloproctol 2014; 30:192-6. 